\title{
The Relationship between Bone Mineral Density and Obesity in Women
}

\author{
Tarfa Albrahim \\ Department of Health Sciences, Clinical Nutrition, College of Health and Rehabilitation Sciences, Princess Nourah Bint, \\ Abdulrahman University, Riyadh, Kingdom of Saudi Arabia \\ Email: t.ibrahim811@gmail.com, tialbrahim@pnu.edu.sa
}

How to cite this paper: Albrahim, T. (2018) The Relationship between Bone Mineral Density and Obesity in Women. Food and Nutrition Sciences, 9, 136-144. https://doi.org/10.4236/fns.2018.92011

Received: December 22, 2017

Accepted: February 25, 2018

Published: February 28, 2018

Copyright $\odot 2018$ by author and Scientific Research Publishing Inc. This work is licensed under the Creative Commons Attribution International License (CC BY 4.0).

http://creativecommons.org/licenses/by/4.0/

\section{c) (i) Open Access}

\begin{abstract}
The aim of this study was to determine the relationship between obesity and osteoporosis. A total of 30 Saudi women, aged between 20 and 50 years, were selected randomly. We calculated each subject's body mass index (BMI) and determined their lumbar and femur bone mineral densities using dual-energy $\mathrm{X}$-ray absorptiometry (DXA). We examined the interaction between obesity and bone mineral density (BMD) using logistic regression, after adjusting for age, family history of osteoporosis, maternal fractures, smoking, and any sedentary lifestyles. BMI was shown to be the most effective independent variable with respect to bone density. We evaluated the Pearson correlation coefficients of BMI, BMD of the lumbar spine, and BMD of the femoral neck with reference to the variables of the study, and found a significant correlation ( $P$ $<0.05$ ) between obesity and osteoporosis. In conclusion, we showed that obese women $\left(\mathrm{BMI}>30 \mathrm{~kg} / \mathrm{m}^{2}\right)$ were at increased risk of osteoporosis at the femoral neck and severe osteopenia in the lumbar spine.
\end{abstract}

\section{Keywords}

Obesity, Osteoporosis, Body Mass Index, Bone Mineral Density, Osteopenia

\section{Introduction}

Obesity is one of the main health problems affecting both developing and developed countries; obesity has reached epidemic proportions and threatens the health of individuals and communities [1]. In the United States, more than 60 percent of the population is obese [2].

An exploratory study in Saudi Arabia reported that the obesity rate was 23 percent among males and 30 percent among females aged between 18 and 30 years, increasing to 39 percent in males and 47 percent in females who were be- 
tween 30 and 50 years of age, and reaching 56 percent in males and 58 percent in females between 50 and 60 years of age [3].

Obese people are more susceptible to diseases than those of moderate weight [4]. Morbidly obese individuals are at high risk of developing diabetes, hypertension and cardiovascular disease. These conditions remain the leading causes of death globally [5]. Osteoporosis is defined as a loss of basic metals from bones. It increases susceptibility to bone fractures involving the lumbar spine, femoral neck and wrist [6] [7].

This research aimed to determine the relationship between obesity and bone density in Saudi women.

\section{Materials and Methods}

We studied a random sample of 30 women attending the obesity clinic at King Faisal Specialist Hospital and Research Center in Riyadh. We used a cluster sample. We selected the summer season of 2015 at random, and randomly selected three weeks of that season to collect data regarding women who attended during that period. The protocol of this study was approved by the research ethics committee and informed consent was acquired from each of the women, who agreed to participate voluntarily. The patients' ages ranged between 20 and 50 years.

\subsection{Procedures}

\section{Completion of the Questionnaire}

Data were collected using a questionnaire which elicited the necessary information to achieve the goals of the study. The questionnaire was completed through personal interviews with women who agreed to participate.

The questionnaire collected the following data:

- Demographic figures including age;

- Anthropometric measurements including body weight and height, from which was calculated each person's body mass index (BMI);

- Health history and nutritional information, including daily food consumption that might affect bone density.

- Questions were asked on the following topics:

- How much each participant was exposed to sunlight, including the frequency and amount of time of exposure, and which parts of the body were exposed to sunlight;

- Quantities of cigarette smoking and duration of smoking;

- Pregnancy status and breastfeeding;

- Physical activity.

The lumbar and femur BMDs were determined using dual-energy X-ray absorptiometry (DXA). DXA is considered one of the most widespread and accurate methods for determining BMD. To perform DXA, the patient is placed in the supine position with the knees raised, and the legs are placed on a special frame to measure the bone density of the pelvis. Then the legs are straightened 
to measure the spine bone density. One beam passes through the bone while a second beam passes through the muscles and tissues. Bone density is determined by computers connected to the device. Upon completion of the examination, which takes less than 30 minutes, information can be acquired that includes the BMD of the examined area. The results of the DXA examination can be divided into three groups (normal, showing osteopenia, and showing osteoporosis).

\subsection{Statistical Analysis}

The data were analysed using the statistical package for the social sciences (SPSS).The results were expressed as percentages, with the mean and standard deviations for the samples. A Pearson correlation coefficient was used to determine the relationship between variables. One-way analysis of variance (ANOVA) was used to determine the significance of differences between variables $(\mathrm{P}<0.05$ was taken as significant). Multiple linear regressions were used to determine the effect of study variables on bone density. Step-wise regression was employed to identify the most influential variables in the study.

\section{Results}

\subsection{Sample Description}

The study was conducted to improve understanding of the relationship between obesity and bone density. A random sample of 30 women aged between 20 and 50 years was obtained. The results are shown in Table 1.

The average age of the sample was 43 years (standard deviation $=17.8$ years). The average BMI was $32.14 \mathrm{~kg} / \mathrm{m}^{2}$, and the average lumbar bone density and femoral neck bone density was $0.93 \mathrm{gm} / \mathrm{cm}^{2}$ and $0.80 \mathrm{gm} / \mathrm{cm}^{2}$, respectively.

The World Health Organization uses a T-score for classification of bone density. The average $\mathrm{T}$-score indicated that most individuals (56.7\%) had weak lumbar spine bones and nearly two-thirds (64.7\%) had weak femoral neck bones (Table 1).

\subsection{Information about Lifestyle of Study Sample}

The results show that most of the participants (57\%) were exposed to sunlight at least twice a week (Table 1). Sixty percent of the sample had experienced three or more pregnancies and just over half of the participants (53.3\%) had breastfed. Seventy percent of the group had irregular menstrual cycles. Table 1 shows that most of the women (60\%) engaged in regular exercise of at least 10 minutes per day.

Only seven percent of the study subjects were smokers and a very small percentage (3.3\%) reported suffering from chronic diseases (hypertension, diabetes mellitus, and thyroid disease). As shown in Table 1, 67 percent of the participants took supplements, mainly calcium and vitamin D.

The study shows that 43.3 percent of the group consumed one glass of milk and milk products per day, while only a small percentage (6.7\%) consumed the recommended amount, which is three glasses (Table 1). 
Table 1. Patient characteristics.

\begin{tabular}{|c|c|}
\hline & Mean \pm SD \\
\hline Age & $43 \pm 7.80$ \\
\hline Height & $156.83 \pm 8.51$ \\
\hline Weight & $79.49 \pm 14.10$ \\
\hline BMI & $32 \pm 3.50$ \\
\hline BMD lumbar spine $\left(\mathrm{g} / \mathrm{cm}^{2}\right)$ & $0.9 \pm 0.17$ \\
\hline BMD femoral neck $\left(\mathrm{g} / \mathrm{cm}^{2}\right)$ & $0.8 \pm 0.15$ \\
\hline T-score BMD L & $-1.15 \pm 1.2$ \\
\hline T-score BMD N & $-1.17 \pm 1.2$ \\
\hline Normal & $8(26.7 \%)$ \\
\hline Osteopenia & $17(56.7 \%)$ \\
\hline Osteoporosis & $5(16.7 \%)$ \\
\hline Normal & $11(36.7 \%)$ \\
\hline Osteopenia & $14(46.7 \%)$ \\
\hline Osteoporosis & $5(16.7 \%)$ \\
\hline Exposed to sunlight $\geq 2$ times/week & $17(57 \%)$ \\
\hline Number of pregnancies $\geq 3$ & $18(60 \%)$ \\
\hline Breastfeeding duration (Month) & $16(53 \%)$ \\
\hline Irregular menstrual cycles $(+)$ & $21(70 \%)$ \\
\hline Irregular menstrual cycles (-) & $9(30 \%)$ \\
\hline Regular exercise $\geq 10 \mathrm{~min} /$ day & $18(60 \%)$ \\
\hline Smoking $(+)$ & $2(7 \%)$ \\
\hline Smoking $(-)$ & $28(93) \%$ \\
\hline $\begin{array}{c}\text { Chronic diseases } \\
\text { Hypertension, diabetes mellitus, and thyroid disease }\end{array}$ & $1(3.3 \%)$ \\
\hline $\begin{array}{l}\text { Supplement use } \\
\text { Calcium and vitamin D }\end{array}$ & $20(67 \%)$ \\
\hline Dairy product consumption $\geq 2$ cups/day & $19(63 \%)$ \\
\hline Caffeine (coffee and tea) consumption $\geq 3$ cups/day & $12(40 \%)$ \\
\hline Soft drinks $\geq$ cup/day & $5(17 \%)$ \\
\hline
\end{tabular}

Coffee and tea were the most popular drinks compared with other caffeine-containing beverages. It was found that 40 percent of women consumed between three and five cups of coffee and tea daily. The majority of individuals (80\%) did not drink carbonated beverages.

To calculate the type and strength of the relationship between independent and dependent variables, the Pearson correlation coefficient was used. It was shown to have an inverse relationship $(\mathrm{P}<0.05)$ between BMI, as an independent variable, and BMD of the lumbar spine and of the femoral neck as dependent variables. Thus the greater the BMI, the lower the bone density (Table 2). 
Table 2. Pearson's correlation coefficients between BMI, BMDL, and BMDN and study variables.

\begin{tabular}{cccc}
\hline Study variables & BMI & BMDL & BMDN \\
\hline Age & 0.29 & -0.34 & -0.28 \\
Height & 0.319 & 0.275 & 0.294 \\
Weight & $0.822^{* *}$ & -0.084 & -0.074 \\
BMI & - & $-0.36^{*}$ & $-0.44^{*}$ \\
Exposures to the sun two or three times/week & & & \\
for about 10 to 15 minutes each & 0.007 & 0.15 & $0.25^{*}$ \\
$\quad$ Physical activity/week & - & 0.12 & $0.41^{*}$ \\
Dairy product intake (cups/day) & -0.04 & $0.43^{*}$ & 0.05 \\
Green leaf vegetables (cups) & -0.17 & $0.37^{*}$ & 0.32 \\
Caffeinated beverages (cups) & 0.28 & -0.25 & -0.20 \\
Number of pregnancies & 0.08 & -0.26 & -0.18 \\
\hline
\end{tabular}

${ }^{*}$ Significant at a $\mathrm{P}<0.05 .{ }^{*}$ Significant at a $\mathrm{P}<0.01$.

The results also show a positive relationship $(\mathrm{P}<0.05)$ between exposures to the sun two or three times a week for about 10 to 15 minutes each and BMD of the femoral neck.

Also, there was a positive relationship $(\mathrm{P}<0.05)$ between the amount of physical activity per week and BMD of the femoral neck. There was a statistically significant relationship $(\mathrm{P}<0.05)$ between consumption of dairy products per day and the BMD of the lumbar spine.

The results in Table 3 indicate that obese women in the study (BMI $>30$ $\mathrm{kg} / \mathrm{m}^{2}$ ) had osteoporosis of the femoral neck and severe osteopenia of the lumbar spine.

All the women in this study showed decreased BMD regardless of regularity of their menstrual cycles. Bone density of the lumbar spine was normal in women who were exposed to sunlight, while BMD of the femoral neck was normal in women who engaged in physical activity. There was a loss of BMD with low intake of milk and milk products.

Table 4 indicates that there were no statistically significant differences between the BMIs of the respondents as a function of BMD in the lumbar spine (T-score). This is shown by the insignificant $\mathrm{F}$ value $(\mathrm{P}<0.07)$. However, Table 5 indicates the presence of statistically significant differences between BMIs of respondents as a function of the BMD of the femoral neck (T-score). This is shown by a significant $\mathrm{F}$ value $(\mathrm{P}<0.01)$. The Scheffe test was used to detect the source of these differences (Table 6).

\subsection{Accounting for Differences in BMI}

Table 6 shows there were statistically significant differences $(\mathrm{P}<0.05)$ between the BMIs of individuals with normal BMD and the BMIs of those with low BMD. The latter group had higher BMI figures. Specifically, women with second-degree obesity $\left(35 \mathrm{~kg} / \mathrm{m}^{2}\right.$ to $\left.39.9 \mathrm{~kg} / \mathrm{m}^{2}\right)$ had osteoporosis, while women with first-degree 
Table 3. Relationship between factors affecting bone density.

\begin{tabular}{cccc}
\hline Factors that affect bone density & Lumbar spine & $\begin{array}{c}\text { Femoral neck } \\
\left(\mathrm{T}-\text { score }^{*}\right)\end{array}$ & -1 -score) \\
\hline BMI & $>30 \mathrm{~kg} / \mathrm{m}^{2}$ & -1.9750 & -2.0500 \\
Irregular menstrual cycle & $(+)$ & -1.1190 & -1.0238 \\
Exposure to the sun & $(-)$ & -1.233 & -1.5111 \\
& $(+)$ & -0.9250 & -1.0400 \\
Physical activity & $(-)$ & -1.6100 & -1.4300 \\
& $(+)$ & -1.306 & -0.716 \\
Consumption of & $(-)$ & -1.238 & -1.796 \\
dairy products & 1 cup/day & -1.1077 & -0.8923 \\
& 2 cup/day & -1.1083 & -1.4333 \\
& 3 cup/day & -0.6500 & -0.2500 \\
\hline
\end{tabular}

${ }^{*}$ T-score: $>-1$ (Normal bone mass). T-score: between -1 and -2.5 : (osteopenia). T-score: $<-2.5$ (osteoporosis) (+): Yes. (-): No.

Table 4. One-way ANOVA (F) of the significance of differences in BMI as a function of the BMDL T-score.

\begin{tabular}{lccccc}
\hline Contrast source & Sum of squares & df & Mean of squares & F & Significance \\
\hline Between groups & 62.43 & 2 & 31.22 & 2.86 & 0.07 \\
Within groups & 294.62 & 27 & 10.91 & & \\
\hline
\end{tabular}

Table 5. One-way ANOVA (F) of the significance of differences in BMI as a function of the BMDN T-score.

\begin{tabular}{cccccc}
\hline Source of variation & Sum of squares & df & Mean of squares & F value & Significance \\
\hline Between groups & 100.31 & 2 & 50.15 & 5.27 & \multirow{2}{*}{0.01} \\
Within groups & 256.74 & 27 & 9.51 & & \\
\hline
\end{tabular}

${ }^{*}$ Significant at a $\mathrm{P}<0.01$.

Table 6. Scheffe's test to clarify the source of differences in BMI as a function of BMDN (T-score).

\begin{tabular}{cccccc}
\hline BMD & Mean of BMI & Normal & Osteopenia & Osteoporosis & Significant \\
\hline Normal & 30.03 & & & \\
Osteopenia & 32.70 & & & \\
Osteoporosis & 35.20 & $*$ & & $<-2.5$ osteoporosis \\
\hline
\end{tabular}

${ }^{*}$ Significant at a $\mathrm{P}<0.05$. T-score $>-1$ (normal bone mass). T-score between -1 and -2.5 (osteopenia). $\mathrm{T}$-score $<-2.5$ (osteoporosis).

obesity $\left(30 \mathrm{~kg} / \mathrm{m}^{2}\right.$ to $34.9 \mathrm{~kg} / \mathrm{m}^{2}$ ) had osteopenia. Thus as obesity increases, the loss of BMD increases.

Multiple linear regression analysis was used to determine the impact of independent factors on BMD. It was found that there was a linear correlation value $(\mathrm{R}=0.757)$ between bone density variables and other study variables, such as age, BMI, times of physical activity per week, consumption of dairy products per day., This value is called the multiple correction between bone density in the femoral neck (BMDN) and study variables (Table 7). The "R2" value is a square 
Table 7. Multiple linear regressions of the study variables on the bone density model.

\begin{tabular}{cccc}
\hline Model & Correlation coefficient & Square of correlation coefficient & Standard error \\
\hline Femoral neck & 0.770 & 0.593 & 1.05 \\
Lumbar spine & 0.757 & 0.573 & 1.03 \\
\hline
\end{tabular}

Table 8. ANOVA to clarify the effect of BMI on bone density.

\begin{tabular}{ccccccc}
\hline \multicolumn{2}{c}{ Source of variation } & $\begin{array}{c}\text { Sum of } \\
\text { squares }\end{array}$ & $\begin{array}{c}\text { Degrees of } \\
\text { freedom }\end{array}$ & $\begin{array}{c}\text { Mean of } \\
\text { squares }\end{array}$ & F value & Sig. \\
\hline Femoral neck & Regression & 11.386 & 1 & 11.386 & 7.389 & $0.01^{*}$ \\
& Residual & 23.360 & 21 & 1.541 & & \\
& Total & 43.746 & 22 & & & \\
Lumbar spin & Regression & 10.602 & 1 & 10.602 & 7.593 & $0.01^{*}$ \\
& Residual & 29.322 & 21 & 1.396 & & \\
& Total & 39.924 & 22 & & & \\
\hline
\end{tabular}

*Significant at $\mathrm{P}<0.01$.

value for the multiple correlation coefficient (0.573), which indicates that study variables are explained by the variation in lumbar spine variables by $57 \%$, and the variation in the femoral neck variable by $59 \%$, and the remainder of the value is due to random errors. The gradual regression method was used to determine the most effective variable of the study on bone density, and it was found that the BMI was the most significant effective independent variable on bone density $\mathrm{P}<0.01$ (Table 8).

\section{Discussion}

This study was conducted to determine the relationship between obesity and bone density in a sample of Saudi women. The study group had an average age of 43 years.

The average BMI was $32 \mathrm{~kg} / \mathrm{m}^{2}$, and the average bone density was low, which indicated a loss of bone density (Table 1). Many previous studies refer to the role of sunlight exposure in bone building by converting vitamin 25 hydroxyvitamin D (25OHD) to the hormonal form 1,25-dihydroxyvitamin D (1,25(OH)2D), which is responsible for the synthesis of calcium carrier-protein [8]. In this study, we observed that average bone density in women exposed to sunlight was normal, while those who were not exposed to sunlight had low bone density in the lumbar spine (Table 1). With respect to the femoral neck, there was loss of bone density, which is considered a risk indicator for pre-osteoporosis, possibly because there are other factors affecting bone density.

A recent study indicated the partial role of estrogen in maintaining bone density [9]. The present study showed no difference between obese women with regular menstrual cycles and those who had irregular menstrual cycles; both groups of women had bone density loss (Table 3). This confirms the presence of 
other factors causing loss of bone density. In addition, most of the study individuals consumed fewer servings of milk and milk products (Table 3 ) than the recommended amount of three cups per day [10]. Women with normal bone density consumed a greater average number of servings of milk and milk products than women with low bone density, although the difference was not significant (Table 3). This finding confirms the role of dairy products in bone building. Dairy products are considered the most important source of several essential nutrients, including calcium, magnesium, phosphorus, potassium, protein and vitamin $\mathrm{D}$, that work together to help protect bones [11].

Most women who took part in the present study took regular walks, which could increase bone density and prevent bone fractures in females before menopause. Women who engaged in physical activity had normal bone density of the femoral neck (Table 3). Thus, awareness regarding the role of dietary calcium intake and the need to practice weight-bearing exercise were important.

Many factors may be related to bone density. Obesity is one of the major considerations affecting bone density in the lumbar spine and femoral neck as compared with other factors. We conclude that the BMI of participants in this study was the strongest factor causing bone loss $(\mathrm{P}<0.01)$. We also showed an inverse relationship between obesity and bone density $(\mathrm{P}<0.05)$.

This study is in agreement with others which suggest that obesity is a co-factor for osteoporosis in the presence of other factors [4] [12]. Similarly, Dela et al. (2005) conclude that obesity is one of the main factors leading to loss of bone density and increases in the number of bone fractures compared with their occurrence in people of normal weight, if they are the same age, sex, and race [13].

The results in the present study indicate that a high degree of obesity increases bone loss. This is consistent with the findings of Núnez et al. (2007), who conclude that obese individuals have lower bone density compared with overweight individuals. This highlights the need to focus on the treatment of obesity because it is a main cause of many chronic and serious diseases, such as osteoporosis [14].

\section{Conflicts of Interest}

The authors declare no conflicts of interest regarding the publication of this paper.

\section{References}

[1] World Health Organization (2003) The WHO Obesity Reports. Geneva, Switzerland.

[2] National Center for Health Statistics (NCHSIIII) (2005) Prevalence of Overweight and Obesity among Adults [Monograph on the Internet]. Hyattsville (MD). National Center for Health Statistics, Centers for Disease Control and Prevention, US Department of Health and Human Services.

http://www.cdc.gov/nchs/products/pubs/pubd/hestats/overweight 
[3] Al-Nozha, M.M., Al-Mazrou, Y.Y., Al-Maatouq, M.A., Arafah, M.R., Khalil, M.Z., Khan, N.B., Al-Marzouki, K., Abdullah, M.A., Al-Khadra, A.H., Al-Harthi, S.S., Al-Shahid, M.S., Al-Mobeireek, A. and Nouh, M.S. (2005) Obesity in Saudi Arabia. Saudi Medical Journal, 26, 824-829.

[4] Higgins, M., Kannel, W., Garrison, R., Pinsky, J. and Stokes, J. (1988) Hazards of Obesity-The Framingham Experience. Acta Medica Scandinavica, 723, S23-S36.

[5] Must, A., Spadano, J., Coakley, E.H., Field, A.E., Colditz, G. and Dietz, W.H. (1999) The Disease Burden Associated with Overweight and Obesity. JAMA, 282, 1523-1529. https://doi.org/10.1001/jama.282.16.1523

[6] Clifford, J.R. and Mary, L. (2006) Mechanisms of Disease: Is Osteoporosis the Obesity of Bone? Nature. Clinical. Practice. Rheumatology, 2, 35-43. https://doi.org/10.1038/ncprheum0070

[7] Fu, X., Ma, X., Lu, H., He, W., Wang, Z. and Zhu, S. (2010) Associations of Fat Mass and Fat Distribution with Bone Mineral Density in Pre- and Postmenopausal Chinese Women. Osteoporosis International. [Epub Ahead of Print].

[8] Zehnder, D., Bland, R., Williams, M.C., et al. (2001) Extrarenal Expression of 25-Hydroxyvitamin D(3)-1a-Hydroxylase. The Journal of Clinical Endocrinology \& Metabolism, 86, 888-894.

[9] Tucker, K.L., Morita, K., Qiao, N., Hannan, M.T., Cupples, L.A. and Kiel, D.P. (2006) Colas, But Not Other Carbonated Beverages, Are Associated with Low Bone Mineral Density in Older Women: The Framingham Osteoporosis Study. The American Journal of Clinical Nutrition, 84, 936-942.

[10] Huth, P.J., Dirienzo, D.B. and Miller, G.D. (2006) Major Scientific Advances with Dairy Foods in Nutrition and Health. Journal of Dairy Science, 89, 1207-1221. https://doi.org/10.3168/jds.S0022-0302(06)72190-7

[11] Merritt, J., Qi, F. and Shi, W. (2006) Milk Helps Build Strong Teeth and Promotes Oral Health. Journal of the California Dental Association, 34, 361-366.

[12] Shipley, M., Black, C.M., Denton, C., Compston, J. and Ogradaigh. (2005) Osteoporois in Kumar and Clark, Clinical Medicine. 6th Edition, Elsevier Saunders, 529-604.

[13] De Leat. C., Kanis, J.A., Oden, A., Johanson, H., Johnell, O., Delmas, P., Eisman, J.A., Kroger, H., Fujiwara, S., Garnero, P., McCloskey, E.V., Mellstrom, D., Melton, L.J., Meunier, P.J., Pols, H.A., Reeve, J., Silman, A. and Tenenhouse, A. (2005) Body Mass Index as a Predictor of Fracture Risk: A Meta-Analysis. Osteoporosis International, 16, 1330-1338.

[14] Nunez, N.P., Carpenter, C.L. and Perkins, S.N. (2007) Extreme Obesity Reduces Bone Mineral Density: Complementary Evidence from Mice and Women. Obesity, 15, 1980-1987. 